DOI: $10.17805 / z p u .2015 .3 .10$

\title{
Имагология и имагопоэтика
}

\author{
В. П. ТРЫКОВ \\ (МОСКОВСКИЙ ПЕДАГОГИЧЕСКИЙ ГОСУДАРСТВЕННЫЙ УНИВЕРСИТЕТ)
}

В статье дан критический анализ имагологии, описана специфика ее методологии, показана связь имагологического подхода к изучению образа Другого с традициями аналитической философии, постструктуралистскими доктринами и методом дискурс-анализа. Рассмотрен вопрос о соотношении имагологии и исторической поэтики. Констатируется роль имагологии в решении некоторых важных политических задач современной Европы, раскрыта латентная идеологичность имагологии. Обосновывается целесообразность введения в научный обиход понятия «имагопоэтика».

Принципиальное отличие имагологии, изучающей образ Другого, от исторической поэтики и компаративистики состоит как в избранном ей аспекте изучения образа, так и в методологии. Имагология изучает прежде всего социально-идеологическую функцию образа Другого, его роль в создании стереотипов и конструировании социокультурной и национальной идентичности, в то время как историческую поэтику интересует структура и художественно-эстетическое функционирование образа. Методом имагологии является постструктуралистский дискурс-анализ. Историческая поэтика использует сравнительно-исторический метод. Философской основой и предпосылкой дискурс-анализа стала аналитическая философия с характерным для нее лингвоцентризмом.

Имагология и историческая поэтика исповедуют разные концепции литературы: для имагологии литература - лишь источник и резервуар стереотипов о Другом, не претендующий на миметическую и познавательную функцию, для исторической поэтики - выражение «духа нации».

Изучая механизмы и способы конструирования социокультурной и национальной идентичности, возможности ее перекодировки посредством создания и распространения стереотипов, имагология выполняет важную для современной Европы политико-культурную задачу - формирование общеевропейской идентичности.

Ключевые слова: имагология, имагопоэтика, дискурс-анализ, историческая поэтика, компаративистика, аналитическая философия, постструктурализм, релятивизм, критицизм.

\section{ВВЕАЕНИЕ}

$\mathrm{B}$ последнее время в научный обиход вошло понятие «имагология» ${ }^{1}$. Более того, как это часто бывает, как все новое и пришедшее с Запада, оно привлекло к себе внимание отечественных исследователей, в некотором роде стало модным. Однако әто понятие зачастую используется некритично, подменяя собой другие, более традиционные понятия и термины: образ заменяется имиджем, сравнительно-исторический подход имагологическим, поэтика - имагологией.

Статус имагологии в современной гуманитаристике остается довольно неопределенным. Большинство исследователей сходятся во мнении, что имагология - сфера гуманитаристики междисциплинарного характера, в которой изучается образ Аругого, чужой страны, народа, культуры. Однако изучением образа (в том числе и образа Аругого) занимаются и другие научные дисциплины, прежде всего историческая поэтика и компаративистика. Существует мнение, что имагология - не самостоятельная дисциплина, а раздел компаративистики. Такой точки зрения придерживаются, в частности, авторы опубликованной в 2013 г. монографии О. Ю. Полякова и О. А. Поляковой «Имагология: теоретико-методологические основы» (Поляков, Полякова, 2013). Генетически имагология действительно тесно связана с компаративистикой, в рамках которой она зародилась в середине XX столетия в ситуации 
кризиса компаративистики как попытка его преодоления за счет переключения исследовательского внимания с изучения влияний, источников и контактных связей на исследование образа Аругого. Эта смена предмета исследования в компаративистике была предложена французским ученым-компаративистом М.-Ф. Гийяром в его книге «Сравнительное литературоведение» (1951): «Не будем больше прослеживать и изучать иллюзорные влияния одной литературы на другую. Аучше попытаемся понять, как формируются и существуют в индивидуальном или коллективном сознании великие мифы о других народах и нациях <... - в этом залог обновления компаративистики, новое направление ее исследований» (Guyard, 1951: 119; пер. мой. - В. Т.).

Однако представляется, что в настоящее время имагология по некоторым важным параметрам - прямой антипод компаративистики (и тесно с ней связанной исторической поэтики), прежде всего это касается целей, аспектов изучения образа Аругого, методологии исследования. В вопросе о методах имагологии нет ясности. Так, О. Ю. и О. А. Поляковы констатируют, что имагология «опирается на весь инструментарий литературоведения, использует поэтологический анализ, нарратологические стратегии, мифопоэтические подходы и т. д.» (Поляков, Полякова, 2013: 7). А. Ю. Большакова говорит об «имагологическом подходе», который, с ее точки зрения, развивается в рамках компаративистики (наряду с типологическим), и характеризует его следующим образом: «...матричную функцию берет на себя образ страны, региона (континента) или известного города. Выстраиваемые здесь сравнительные ряды предполагают зеркальность, взаимоотражение и даже взаимовлияние возможных компонентов» (Проблемы современного ..., 2004: 25) и далее приводит возможные темы имагологического характера: «Образ Запада в русской литературе», «Образ России в литературе Запада», «Москва глазами американских писателей», «Образ Парижа в московской поэзии ХХ века» и т. п. По сути, остаются нераскрытыми сущность и специфика имагологического подхода. О. Ю. Поляков и О. А. Полякова его вообще не вычленяют, а А. Ю. Большакова сводит к предмету исследования - все тому же образу Аругого.

Не проясняет ситуацию и то определение имагологии, которое дано в книге «Россия и Запад в начале нового тысячелетия»: «Имагология - направление, исследующее отношение к действительности как к некоему тексту, когда сам образ понимается не только как элемент, часть и способ изучаемого текста, но и как общее представление о мире, континентах, странах, городах, их обитателях и т. А.» (Россия и Запад ..., 2007: 5). Что такое образ как «способ изучаемого текста»? Является ли исключительной прерогативой имагологии изучение образа как «общего представления о мире, континентах, странах, городах и их обитателях» или образ в этом качестве может изучаться и другими разделами литературоведения, например исторической поэтикой? Аанное определение не столько проясняет ситуацию, сколько запутывает ее и порождает вопросы. Попробуем разобраться.

Один из основателей имагологии - немецкий ученый Х. Аизеринк декларировал в своей программной статье «К проблеме “имиджей” и “миражей” и их исследования в рамках сравнительного литературоведения» (1966), что «образ другой страны не является предметом исследования компаративистики (читай “имагологии”. - B. Т.), однако он становится таковым в том случае, когда литературный имидж или мираж влияет на общественное мнение» (цит. по: Миры образов ..., 2003: 30). Таким образом, имагология, в отличие от компаративистики и исторической поэтики, изуча- 
ет образ Аругого («имидж» в имагологической терминологии) не в художественноэстетической, а в социально-идеологической функции. Компаративистика и историческая поэтика исследуют структуру, смысл и поэтологический, художественно-эстетический статус образа (в том числе и образа Аругого) в литературном произведении, приемы создания образа, его типологию в разных национальных литературах. Иными словами, компаративистику и историческую поэтику образ интересует как творение поэтического сознания в его художественно-эстетической неповторимости, многомерности и многозначности и связях с традицией, «преданием». Здесь уместно вспомнить определение предмета исторической поэтики, данное ее основателем А. Н. Веселовским, - это «эволюция поэтического сознания и его форм» (Веселовский, 1940: 53).

Имагологию же прежде всего интересует вопрос, как образы Аругого, конструируемые в художественной литературе, СМИ, публицистике, искусстве, т. е. в различных типах дискурса, входят в общественное сознание, превращаются в имиджи-стереотипы и формируют представление нации о себе и о других народах. Аитературное произведение берется имагологами не как самостоятельный эстетический феномен, а лишь как источник «имиджей», стереотипизированных, устойчивых и упрощенных образов, транслируемых затем по различным каналам в общественное сознание и определяющих в значительной степени отношение одного народа к другому.

В этом отношении имагология стоит на грани между литературоведением и социологией, социальной психологией. В той мере, в какой имагология в качестве материала для изучения имиджей использует литературные произведения, она смыкается с литературоведением, но, акцентируя изучение социально-психологической, идеологической функции литературных (и шире - художественных) образов, она сближается с социологией и социальной психологией.

Имагология развивается в рамках так называемого cultural turn в современной западной гуманитаристике, следствием которого стало то, что литературоведение утрачивает свою специфику, рассматривается как придаток культурологии, одна из наук о культуре, общая задача которых - понять, как конструируются в общественном сознании те или иные понятия, идеи, концепты, культурная и национальная идентичность. В этом контексте литература рассматривается как один из инструментов социального конструирования ${ }^{2}$. «Аитература (так же как и другие художественно-нарративные медиа, такие как кино) является привилегированным средством распространения стереотипов...» (Иеерссен, 2013: 159).

Некритичным оказывается не только использование понятия «имагология» в современном отечественном дитературоведении. Некритично само отношение к имагологии. Так, О. Ю. Поляков и О. А. Полякова, авторы наиболее обстоятельного на сегодняшний день аналитического обзора по имагологии, дают такую ее оценку: «В настоящее время перспективность новой научной дисциплины не вызывает сомнений» (Поляков, Полякова, 2013: 111). Однако первый долг ученого - сомневаться. Усомнились и мы. И прежде всего в научности имагологической методологии.

\section{АИСКУРС-АНААИЗ КАК МЕТОА ИМАГОАОГИИ}

Существенным отличием имагологии от компаративистики и исторической поэтики является не только различие аспектов изучения образа и конечных целей этого изучения, но и методология. Метод исторической поэтики - сравнительно-исторический. В этом названии важны обе части. Историческая поэтика не просто сравнивает 
разноязычные литературы, но сравнение производится на основе принципа историзма, т. е. «эволюция художественного сознания и его форм» изучается в ее обусловленности динамикой исторического и социокультурного процесса. Аля А. Н. Веселовского и его последователей художественный образ, несомненно, отражение (разумеется, в специфической, художественной форме) исторической реальности. С точки зрения исторической поэтики в художественном сознании «всякий раз отражены историческое содержание той или иной эпохи, ее идеологические потребности и представления, отношения литературы и действительности...» (Категории поэтики ... , 1994: 3).

Напротив, важнейший постулат имагологии - нереференциальность образа Аругого. Авторитетный современный французский имаголог А. Пажо утверждает, что «образ не является более или менее измененным воспроизведением некой реальности...» (Pageaux, 1988: 376; пер. мой. - B. Т.). Можно констатировать принципиальный аисторизм имагологов как исследователей, работающих в постмодернистской парадигме. Имагологию не интересует вопрос о том, насколько создаваемый имидж соответствует референту, как снимается ею вопрос о социокультурной обусловленности имиджа. Акцент переносится на выявление источников образа Аругого, конструирующих его дискурсов, средств и механизмов его трансляции в общественное сознание, т. е. превращения художественного образа (в тех случаях, когда объектом исследования становится художественное произведение) в имидж-стереотип Аругого. Текст перекликается с текстом, образ с образом, но они никак не соотносятся с социокультурной реальностью и ею не обусловливаются. Пространство текстов отрывается от пространства истории, социума. «Имагология изучает репрезентаменты, репрезентации как текстовые стратегии и как дискурс (курсив мой. - В. Т.)» (Иеерссен, 2013: 160). Иными словами, методом имагологии становится постструктурадистский дискурс-анализ, изучающий образ (в том числе и образ Аругого) как результат различных дискурсивных практик, «борьбы дискурсов». Аискурс-анализ не отрицает реальность, но маргинализирует, виртуализирует ее, акцентируя внимание на «воображаемом», придавая ему самостоятельное значение.

Скандинавские исследовательницы $\Lambda$. Филлипс и М. Йоргенсен в книге «Аискурсанализ. Теория и метод» (2002) задаются вопросом, «делает ли релятивизм, свойственный социально-конструкционистской предпосылке, невозможным отличие хороших описаний действительности от плохих...» (Филлипс, Йоргенсен, 2004: 298). Поднимая проблему релятивизма и его последствий для системы знания, они излагают точку зрения некоторых западных исследователей ${ }^{3}$, согласно которой релятивизм это «фундаментальный скептицизм в отношении любого требования знания о действительности, скептицизм, который делает возможность подвергнуть сомнению все. Но это не означает, что мы не можем выносить суждения об этой действительности на самом деле мы не можем этого не делать. Что это означает, так это то, что все суждения открыты для обсуждения, и в этом состоит возможность для продолжающихся демократических дискуссий. Напротив, реалистические аргументы, выявляющие действительную природу мира, замораживают обсуждение» (там же: 299). Таким образом, релятивизм, с точки зрения этих ученых, - «условие для любого производства знания» (там же).

Однако, во-первых, в этих рассуждениях происходит явная подмена понятий. Релятивизм отождествляется с критицизмом, который действительно есть необходимое условие научной позиции. Критицизм предполагает возможность поставить под во- 
прос любые устоявшиеся научные концепции или сложившиеся представления обыденного сознания, допустимость и даже необходимость их аргументированной критики и опровержения. Релятивизм же утверждает равноценность всякого знания, любой позиции, отмену иерархии и в конечном счете как следствие снятие вопроса об истинности или ложности той или иной концепции, того или иного знания, их уравнивание в «субъективности», а значит - «неподлинности». Критицизм имеет своей задачей и следствием уточнение прежних представлений о действительности, постепенное продвижение к более адекватному пониманию реальности. Релятивизм отказывается от оппозиций «истинное - ложное», «хорошее - плохое», «высокое низкое», уравнивая разные идеи, рядополагая их как равноценные, тем самым подрывая саму возможность постановки вопроса о том, какая из научных концепций на данном этапе развития научного знания дает наиболее адекватное описание действительности, исходя из достигнутого наукой на этом этапе уровня.

Заметим, кстати, что такое же отождествление критицизма и релятивизма и увязывание их с ценностями и задачами либеральной демократии находим и в известной книге современного американского мыслителя Ф. Фукуямы «Конец истории» (1992): «Высшее образование в США и других западных странах сегодня обычно прививает молодым людям историческую и релятивистскую точку зрения, свойственную мысли двадцатого века. Это подготавливает их к гражданству в либеральной демократии, поощряя терпимость к чужим взглядам...» (Фукуяма, 2005: 198).

Во-вторых, М. Филлипс и М. В. Йоргенсен априори исходят из того, что «реалистические аргументы», т. е. позиция тех ученых, которые стремятся понять «действительную природу мира», представляет собой преграду на пути свободного обсуждения различных точек зрения, т. е. «демократической» научной дискуссии. Странный тезис, представляющий тех, кто полагает, что истина существует, сущность вещей может быть понята (в том числе и прежде всего при помощи науки), что наука может постепенно продвигаться к все более адекватному представлению о мире, какими-то авторитарными монстрами, не способными к «демократической дискуссии».

Аискурс-анализ - порождение постструктурализма и генетически связанного с ним постмодернизма, которые явились реакцией на «авторитаризм» и «монологизм» функционалистских парадигм (гегельянства, психоанализа, марксизма, структурализма), объединенных представлением о существовании объективных, не зависящих от воли субъекта глобальных «структур» (будь то «Мировой Аух», «Бессознательное», экономические законы или законы языка), определяющих как поведение отдельного индивидуума, так и движение истории. Постструктурализм-постмодернизм стали травматической реакцией западной мысли на тоталитарные тенденции, ярко проявившие себя в XX столетии. Ответственность за идеологическое, интеллектуальное обеспечение политического тоталитаризма была возложена на функционалистские парадигмы.

\section{АНААИТИЧЕСКАЯ ФИАОСОФИЯ - ФИАОСОФСКАЯ ОСНОВА АИСКУРС-АНААИЗА}

Попыткой преодоления функционалистских парадигм стала аналитическая философия ( «философия языка»), которая основывалась на критике «метафизики» функционалистских парадигм и вообще глобальных объясняющих философских систем. Аналитическая философия провозгласила отказ от исследования коренных мировоззренческих проблем онтологического и гносеологического характера (отношения 
субъекта-объекта, материи и духа и т. д.). Все это трактуется аналитической философией как «метафизика», лишенная научно-познавательного значения. Аналитическая философия на новом витке историко-культурного развития продолжает линию философского позитивизма. Способом преодоления «метафизики» функционалистских парадигм становится в аналитической философии изучение механизмов языка. Аналитическая философия ставит задачу понять, как, в каких категориях функционирует язык, а значит, и мышление. Основным предметом изучения становятся отношения между словами и реальностью. Интерес функционалистских парадигм к миру (разным его аспектам) подменяется интересом к языку.

Аингвоцентризм аналитической философии вызывал критику у некоторых крупных философов. Например, Б. Рассел считал, что аналитическая философия уходит от смысла вещей в игру в слова. Критикуя позднего $\Lambda$. Витгенштейна, выдвинувшего в 1920-1930-е годы концепцию языка как комплекса языковых игр, а задачу философии видевшего в том, чтобы понять и описать правила той или иной языковой игры, Б. Рассел писал, что не может поверить, что «теория с подобными меланхолическими последствиями может быть верной», и утверждал, что цель слов «заключается в занятии тем, что отлично от слов» (цит. по: Реале, Антисери, 1997: 456).

Аогика лингвоцентризма была экстраполирована в сферу эстетики и теории литературы, в значительной степени обусловив постструктуралистскую концепцию литературы, отрицающую референциальность литературы. Аля Р. Барта «литература это способ освоения имени» (Барт, 1989: 352). Она не соотносится с реальностью, не отражает и не познает ее. Претензии реализма на правдивое отражение действительности - всего лишь «референциальная иллюзия».

Подобный взгляд на литературу был усвоен сторонниками дискурс-анализа, и в частности имагологами, для которых литература - не эстетический феномен, опосредованно отражающий реальность и претендующий на ее познание, а всего лишь лаборатория для изучения имиджей, резервуар, откуда черпаются образы Аругого, превращающиеся затем в стереотипы.

Аля компаративистики и исторической поэтики как в известном смысле наследниц культурно-исторической школы литература - отражение «духа нации», особенностей национальной культуры, менталитета. Одной из задач сравнительного изучения литератур является выявление их национальной специфики. Аля имагологов в отличие от компаративистов нация - не объективная, исторически сложившаяся данность, но сфера «воображаемого», условный интеллектуальный конструкт, в создании которого значительную роль играют различные дискурсивные практики.

В результате научное объяснение явлений заменяется в постструктурализме множеством субъективных интерпретаций. Характерным становится отождествление действительности и рефлексии о ней, стирание границы между реальным миром и его отражением в человеческом сознании. То есть, по существу, устраняется базовая для науки оппозиция «объект / субъект», а отсюда следует невозможность занять критическую дистанцию по отношению к объекту исследования, а значит, и невозможность научного критического анализа. Сторонники «нового историзма», а вслед за ними и имагологи стирают различие в предметах анализа историка и интерпретатора. Историк работает с фактами, имевшими место в прошлом. Он выявляет и анализирует структуру материала. Интерпретатор создает структуру материала ( ффакты») в процессе его обработки. Постмодернистская релятивизация факта вытекает из концепции дискурсивности любого знания. 


\section{ААТЕНТНАЯ ИАЕОАОГИЧНОСТЬ ИМАГОАОГИИ И ЕЕ ПОАИТИЧЕСКАЯ ФУНКЦИЯ}

Возвращаясь к началу нашей статьи, в которой была приведена цитата о несомненной перспективности имагологии в качестве новой научной дисциплины, зададимся вопросами: может ли быть научной дисциплина, теоретические предпосылки которой и ее метод (дискурс-анализ), как мы стремились показать в настоящей статье, восходят к постмодернистской «философии множественности», отрицающей существование истины, рассматривающей науку как одну из дискурсивных практик, ставящей под сомнение категорию «объективность», отвергающей историзм и заменяющей его мифологией пандискурсивности? Не является ли имагология квазинаукой, разновидностью идеологии, цель которой - стирание национальной идентичности? Не есть ли имагология - идеологическое обоснование и обеспечение процесса глобализации? Но в таком случае чем имагология принципиально отличается от заклейменного вульгарного социологизма? Как и вульгарный социологизм, она, обращаясь к литературному материалу, игнорируют специфику литературы, видит в ней лишь материал и инструмент, редуцирует литературу, по выражению Й. Аеерссена, к «привилегированному средству распространения стереотипов» (цит. по: Поляков, Полякова, 2013: 159).

Вульгарный социологизм рассматривал литературу как отражение и инструмент классовой борьбы, имагология видит в ней средство социокультурной инженерии. Цель имагологии - «деидеологизация национального сознания в целях развития общеевропейской цивилизации и обеспечения гармонического сосуществования (разных европейских народов. $-B . T$.) в пространственно-временном континууме современной истории и культуры» (Миры образов ... , 2003: 13). Иными словами, задача состоит в ослаблении национального самосознания, стирании идентичности европейских наций и формировании единой общеевропейской идентичности. В сущности, политических целей имагологии не скрывал ее родоначальник X. Аизеринк, когда писал в статье «Компаративистская имагология. О политической значимости литературоведения в Европе» (1988): «...В действительности имагология является сегодня тем важным и многообещающим вкладом, который могла внести 150-летняя дисциплина сравнительного литературоведения в понимание и решение специфических проблем, появившихся в результате европейской многонациональности. Сейчас каждое открытие в области имагологии - событие политического значения» (цит. по: Поляков, Полякова, 2013: 152-153).

\section{ЗАКАЮЧЕНИЕ}

Заслуга имагологии в том, что она актуализировала действительно важную сферу научного поиска - все, что связано с изучением образа Аругого. Однако изучать его можно по-разному, с разными целями и разными методами, и прежде всего в рамках литературоведения. Стоит ли науке о литературе ориентироваться на сомнительный дискурс-анализ? Не разумнее ли обратиться к традициями русской филологической школы с ее интересом к специфике литературы (формалисты), с ее широким и системным взглядом на литературу в ее обусловленности социокультурными и историческими факторами? У нас в этом отношении прекрасные учителя, среди которых А. H. Beселовский, Ю. Н. Тынянов, М. М. Бахтин, Ю. М. Аотман, А. С. Аихачев и др.

Аля различения имагологии и той сферы поэтики, которая занимается исследованием образом Аругого, но делает это не с позиций постмодернистского дискурс-ана- 
лиза, а обращаясь к сравнительно-историческому методу и традициям исторической поэтики, представляется целесообразным использовать понятие «имагопоэтика».

\section{ПРИМЕЧАНИЯ}

1 O том, что это понятие укореняется в современной отечественной гуманитаристике, вызывая научную рефлексию авторитетных исследователей, свидетельствует, в частности, статья Вл. А. Аукова «Имагология: тезаурусные расширения» (Иуков, 2012).

2 О влиянии концепции социального конструирования реальности П. Бергера и Т. Аукмана на генезис имагологии писал А. Р. Ощепков (Ощепков, 2010).

3 Показательно, что точка зрения тех ученых, которые видят в релятивизме явление тревожное, отрицательное, «политическое препятствие», лишь упоминается в книге, но не излагается, как, впрочем, даже не названы имена этих ученых, в отличие от представителей второй группы - защитников релятивизма.

\section{СПИСОК АИТЕРАТУРЫ}

Барт, Р. (1989) Избранные работы: Семиотика. Поэтика. М. : Прогресс. 616 с.

Веселовский, А. Н. (1940) Историческая поэтика. А. : Гослитиздат. 649 с.

Категории поэтики в смене литературных эпох (1994) / С. С. Аверинцев, М. А. Андреев, М. А. Гаспаров, П. А. Гринцер, А. В. Михайлов // Историческая поэтика. Аитературные эпохи и типы художественного сознания / ред. П. А. Гринцер. М. : Наследие. 512 с. С. 3-38.

Иеерссен, Й. (2013) Имагология: история и метод// Поляков, О. Ю., Полякова, О. А. Имагология: теоретико-методологические основы. Киров : ООО «Радуга-ПРЕСС». 162 с. С. 159-162.

Ауков, Вл. А. (2012) Имагология: тезаурусные расширения // Имагологические аспекты русской и зарубежных литератур : межвуз. сб. науч. трудов / отв. ред. О. Ю. Поляков. Киров : ООО «Радуга-ПРЕСС». 270 с. С. $15-31$.

Миры образов - Образы мира / Bilderwelten - Weltbilder (2003) : справочник по имагологии : пер. с нем. Волгоград : Перемена. 93 с.

Ощепков, А. Р. (2010) Имагология // Знание. Понимание. Умение. № 1. С. 251-253.

Поляков, О. Ю., Полякова, О. А. (2013) Имагология: теоретико-методологические основы. Киров : ООО «Радуга-ПРЕСС». 162 с.

Проблемы современного сравнительного литературоведения (2004) / под ред. Н. А. Вишневской и А. А. Михайлова. М. : ИМАИ РАН. 96 с.

Реале, Аж., Антисери, А. (1997) Западная философия от истоков до наших дней : в 4 т. СПб. : ТОО ТК «Петрополис». Т. 4: От романтизма до наших дней. 880 с.

Россия и Запад в начале нового тысячелетия (2007) / отв. ред. А. Ю. Большакова. М. : Наука. $325 \mathrm{c}$.

Филлипс, А., Йоргенсен, М. В. (2004) Аискурс-анализ. Теория и метод : пер. с англ. Харьков : Гуманитарный центр. 336 с.

Фукуяма, Ф. (2005) Конец истории и последний человек. М. : АСТ ; Ермак. 588 с.

Guyard, M.-F. (1951) La litturature comparée. Paris : PUF. 126 p.

Pageaux, D.-H. (1988) Image/Imaginaire // Europa und das nationale Selbstversta?ndnis : imagologische Probleme in Literatur, Kunst und Kultur des 19. und 20. Jahrhunderts / hrsg. von H. Dyserinck, K. U. Syndram. Bonn : Bouvier. 435 p. S. 367-380.

Аата поступления: 12.06.2015 г.

\section{IMAGOLOGY AND IMAGOPOETICS \\ V. P. TRYKOV \\ (Moscow State PeDAGOGICAL UnIVERSITY)}

The article provides a critical analysis of imagology, revealing the link between imagological approach to the Other, on the one hand, and the traditions of the analytic philosophy, post-struc- 
turalist doctrines and the method of discourse analysis, on the other. We also consider the problem of imagology's correlation with historical poetics and investigate the role of imagology in solving some crucial political challenges for contemporary Europe, discovering the latent ideological nature of imagology. We also call for the introduction of a new notion, "imagopoetics".

The foundational difference between imagology which studies the image of the Other and comparative studies or historical poetics lies both in the aspect of image studies and its methodology. Imagology primarily concentrates on the social and ideological function of the image of the Other, its role in creating stereotypes and sociocultural and national particularity, while historical politics is interested in the structure and aesthetic operation of the image. Imagology's method is the post-structuralist discourse analysis, while historical poetics utilizes the comparative historical method. Analytical philosophy with its characteristic linguocentrism acts as a forerunner and philosophical background for discourse analysis.

Imagology and historical poetics have different visions of literature. For imagology, literature is nothing more than a source and repository of the stereotypes of the Other. Literature here is devoid of mimetic and cognitive functions, unlike the view of historical poetics, which is focused on the "spirit of the nation".

By studying mechanisms and types of constructing sociocultural and ethnic identities, as well as the chances of recoding it by creating and spreading stereotypes, imagology has a very important poetical and cultural function for contemporary Europe - shaping the common European identity.

Keywords: imagology, imagopoetics, discourse analysis, historical poetics, comparative literature, analytic philosophy, post-structuralism, relativism, criticism.

\section{REFERENCES}

Barthes, R. (1989) Izbrannye raboty: Semiotika. Poetika [Selected works: Semiotics. Poetics]. Moscow, Progress Publ. 616 p. (In Russ.).

Veselovsky, A. N. (1940) Istoricheskaia poetika [Historical poetics]. Leningrad, Goslitizdat Publ. 649 p. (In Russ.).

Kategorii poetiki v smene literaturnykh epoch [The categories of poetics in the change of literary epochs] (1994) / S. S. Averintsev, M. L. Andreev, M. L. Gasparov, P. A. Grintser and A. V. Mikhailov. In: Istoricheskaia poetika. Literaturnye epokbi i tipy kbudozhestvennogo soznaniia [Historical poetics. Literary epochs and types of artistic consciousness]/ ed. by. P. A. Grintser. Moscow, Nasledie Publ. 512 p. Pp. 3-38. (In Russ.).

Leerssen, I. (2013) Imagologiia: istoriia i metod [Imagology: History and method]. In: Poliakov, O. Yu. and Poliakova, O. A. Imagologiia: teoretiko-metodologicheskie osnovy [Imagology: Theoretical and methodological foundations]. Kirov, Raduga-PRESS LLC. 162 p. Pp. 159-162. (In Russ.).

Lukov, Vl. A. (2012) Imagologiia: tezaurusnye rasshireniia [Imagology: Thesaurus extentions]. In: Imagologicheskie aspekty russkoi i zarubezhnykb literatur [Imagological aspects of Russian and foreign literatures] : An interuniversity collection of articles / ed. by O. Yu. Poliakov. Kirov, RadugaPRESS LLC. 270 p. Pp. 15-31. (In Russ.).

Miry obrazov - Obrazy mira / Bilderwelten-Weltbilder [Worlds of images - Images of the world] (2003) : A reference book on imagology. Volgograd, Peremena Publ. 93 p. (In Russ.).

Oshchepkov, A. R. (2010) Imagologiia [Imagology]. Znanie. Ponimanie. Umenie, no. 1, pp. 251-253. (In Russ.).

Poliakov, O. Yu. and Poliakova, O. A. (2013) Imagologiia: teoretiko-metodologicheskie osnovy [Imagology: Theoretical and methodological foundations]. Kirov, Raduga-PRESS LLC. 162 p. (In Russ.).

Problemy sovremennogo sravnitel' nogo literaturovedeniia [Issues of contemporary literary studies] (2004) / ed. by N. A. Vishnevskaia and A. D. Mikhailov. Moscow, Publ. House of the Institute of World Literature, RAS. 96 p. (In Russ.).

Reale, G. and Antiseri, D. (1997) Zapadnaia filosofiia ot istokov do nashikb dnei [Western philosophy from its origins to the present day]: in 4 vols. St. Petersburg, Petropolis Publ. Vol. 4: Ot romantizma do nashikh dnei [From Romanticism to our days]. 880 p. (In Russ.). 
Rossiia $i$ Zapad $v$ nachale novogo tysiacheletiia [Russia and the West at the start of the new millennium] (2007) / ed. by A. Yu. Bolshakova. Moscow, Nauka Publ. 325, [1] p. (In Russ.).

Phillips, L. and Jorgensen, M. V. (2004) Diskurs-analiz. Teoriia i metod [Discourse analysis as theory and method]. Kharkov, Gumanitarnyi tsentr Publ. 336 p. (In Russ.).

Fukuyama, F. (2005) Konets istorii i poslednii chelovek [The end of history and the last man]. Moscow, AST Publ ; Ermak Publ. 588 p. (In Russ.).

Guyard, M.-F. (1951) La litturature comparée. Paris, PUF. 126, [2] p. (In Fr.).

Pageaux, D.-H. (1988) Image/Imaginaire. In: Europa und das nationale Selbstverstandnis : imagologische Probleme in Literatur, Kunst und Kultur des 19. und 20. Jabrbunderts / ed. by H. Dyserinck and K. U. Syndram. Bonn, Bouvier Publ. 435 p. Pp. 367-380. (In Fr.).

Submission date: 12.06 .2015 .

Трыков Валерий Павлович - доктор филологических наук, профессор кафедры всемирной литературы Московского педагогического государственного университета, академик Международной академии наук (IAS, Инсбрук, Австрия). Адрес: 119435, Россия, г. Москва, ул. Малая Пироговская, д. 1. Тел.: +7 (495) 735-59-48. Эл. адрес: alex18@sumail.ru

Trykov Valery Pavlovich, Doctor of Philology, Professor, Department of World Literature, Moscow State Pedagogical University; Full member, International Academy of Science (Innsbruck, Austria). Postal address: 1 Malaya Pirogovskaya, 119435 Moscow, Russian Federation. Tel.: +7 (495) 735-59-48. E-mail: alex18@sumail.ru 